University of Nebraska - Lincoln

DigitalCommons@University of Nebraska - Lincoln

August 1975

\title{
Gauge invariance and radiative transition probabilities
}

Ian P. Grant

Oxford University, ipg@maths.ox.ac.uk

Anthony F. Starace

University of Nebraska-Lincoln, astarace1@unl.edu

Follow this and additional works at: https://digitalcommons.unl.edu/physicsstarace

Part of the Physics Commons

Grant, lan P. and Starace, Anthony F., "Gauge invariance and radiative transition probabilities" (1975). Anthony F. Starace Publications. 160.

https://digitalcommons.unl.edu/physicsstarace/160

This Article is brought to you for free and open access by the Research Papers in Physics and Astronomy at DigitalCommons@University of Nebraska - Lincoln. It has been accepted for inclusion in Anthony F. Starace Publications by an authorized administrator of DigitalCommons@University of Nebraska - Lincoln. 
Published in Journal of Physics B: Atomic and Molecular Physics 8:12 (August 21, 1975), pp. 1999-2000. Copyright ( 1975 The Institute of Physics. Used by permission.

http://www.iop.org/EJ/journal/IPhysB

Submitted February 3, 1975; revised April 16, 1975.

\title{
Gauge invariance and radiative transition probabilities
}

\author{
I. P. Grant \\ Department of Theoretical Chemistry, Oxford University, Oxford OX1 3TG, England
}

\author{
A. F. Starace \\ Department of Physics, University of Nebraska-Lincoln, Lincoln, Nebraska 68508, \\ USA
}

\begin{abstract}
The relationship between recommendations of some recent papers on the choice of formula (length, velocity, or acceleration type) for calculating radiative transition probabilities is clarified.
\end{abstract}

The problem of choosing the appropriate formula for use in oscillator strength calculations for many-electron systems has been discussed in a number of recent papers (Starace 1971, 1973, Grant 1974). The key difficulty is that the interaction between electrons and the radiation field is not gauge invariant unless the electron charge distribution satisfies exactly a continuity equation. This has the unfortunate consequence that transition probabilities for electric multipoles (but not magnetic multipoles), evaluated with approximate wavefunctions, depend on the choice of gauge and so are in general not unique. Our earlier papers contain apparently conflicting recommendations for overcoming the difficulty.

The paper of Starace (1971) is written in the spirit of earlier work by Sachs and Austern (1951) and Korolev (1968). Let $H_{\text {mod }}$ be a model Hamiltonian for a manyelectron system. Construct a Hamiltonian describing the interaction of this system with the electromagnetic field by making the usual replacement $p \rightarrow p-e A$ and then demand that the resulting operator be gauge invariant. This method of enforcing gauge invariance leads to a unique interaction operator proportional to the commutator $\left[H_{\text {mod }}, D_{l}\right]$, where $D_{l}$ is a multipole operator of order $l$. For electric-dipole transitions, the commutator only yields the dipole velocity or dipole acceleration operators for local potentials, whereas for both local and non-local potentials, it may be easily written in terms of the dipole length formula. This leads Starace to recommend the use of the dipole length form for problems in which $H_{\text {mod }}$ contains a non-local potential, for example Hartree-Fock or CI calculations. On the other hand, the relativistic theory of radiative transitions described by Grant (1974) focuses attention on the (covariant) interaction Hamiltonian. He suggests that one should make a consistent choice of gauge for the (exact) atomic Hamiltonian and the interaction Hamiltonian so that gauge invariance is guaranteed for the combined electron-photon system. The conventional choice of the Coulomb gauge for the atomic Hamiltonian implies use of the dipole velocity operator for the interaction in the non-relativistic limit. Other gauges lead to a linear combination of the dipole velocity and dipole length operators in the non-relativistic limit, the result only being gauge independent if the charge distribution 
satisfies an exact continuity equation. This is equivalent to requiring the Hamiltonian for the isolated atom (or molecule) to be gauge invariant in the sense used by Starace.

It appears, then, that there are essentially two ways of looking at the matter. One can either follow Starace, take a model Hamiltonian and employ it in as realistic a way as possible by requiring it to be gauge invariant as described above; or one can regard the model Hamiltonian as an approximation to the truth and accept its lack of gauge invariance as a possible measure of inaccuracy (though of course not the only one). There is some evidence from recent calculations to suggest the latter may be a fruitful interpretation. For example, Hibbert (1974) reports an extensive series of calculations of oscillator strengths, in both length and velocity forms, for transitions between $1 \mathrm{~s}^{2} 2 \mathrm{~s} 2 \mathrm{p}$ and $1 \mathrm{~s}^{2} 2 \mathrm{p}^{2}$ states $\left({ }^{3} \mathrm{P}^{\mathrm{o}} \rightarrow{ }^{3} \mathrm{Pe},{ }^{1} \mathrm{Po}^{\mathrm{o}} \rightarrow{ }^{1} \mathrm{D}^{\mathrm{e}}\right.$, ${ }^{1} \mathrm{Po}^{\mathrm{o}} \rightarrow{ }^{1} \mathrm{~S}$ ) in the beryllium isoelectronic sequence. Starting from a discrepancy for single-configuration HF values of about a factor of 2 , and using CI wavefunctions of various degrees of complexity, he has found it possible to make the length and velocity values agree within a few per cent in most cases. He finds that the length expression shows the smaller change as more configurations are introduced, the velocity form being apparently more sensitive to the choice of wavefunctions.

Such calculations are expensive, and Hibbert's results suggest that Starace's proposal, which selects a unique transition operator from the infinite number available, may be preferred for more approximate work. However, this cannot yet be regarded as completely proven, and it is clear that there is still much to be done before the last word can be said on the subject.

\section{References}

Grant, I. P. 1974 J. Phys. B: Atom. Molec. Phys. 7: 1458-75

Hibbert, A. 1974 J. Phys. B: Atom. Molec. Phys. 7: 1417-34

Korolev, A. M. 1968 Soc. J. Nucl. Phys. 6: 257-61

Sachs, R. G., and Austern, N. 1951 Phys. Rev. 81: 705-9

Starace, A. F. 1971 Phys. Rev. A 3: 1242-5 